\title{
CONTROLE DE PLANTAS DANINHAS EM ARROZ IRRIGADO MEDIANTE O MOMENTO DA ADMISSÃo E DA ALTURA dA LÂMINA dE ÁGUA ( $\left.{ }^{1}\right)$
}

\author{
ENES FURLANI JUNIOR $\left({ }^{2,4}\right)$, JOSÉ RICARDO MACHADO $\left({ }^{3}\right)$ e EDIVALDO DOMINGUES VELINI $\left({ }^{3}\right)$
}

\begin{abstract}
RESUMO
Este trabalho, desenvolvido ao nível de campo, na Fazenda Experimental Edgárdia, da Faculdade de Ciências Agronômicas da UNESP, Botucatu, no ano agrícola 1990/91, objetivou avaliar os efeitos do momento de admissão da água e da altura da lâmina de água sobre o desenvolvimento das plantas daninhas e os reflexos sobre as de arroz. O delineamento experimental usado foi de blocos ao acaso com parcelas subsubdivididas. Às parcelas, corresponderam os momentos de admissão de água M1, M2 e M3, respectivamente, 15, 42 e 74 dias após a emergência das plantas de arroz. As subparcelas corresponderam às alturas das lâminas de água L5, L10 e $L 15$, respectivamente, 5,10 e $15 \mathrm{~cm}$ e as subsubparcelas, a dois sistemas de conduçāo: com capina (cc) e sem capina (sc). Verificou-se que o desenvolvimento das plantas daninhas foi afetado tanto pelo momento de admissão de água como pela altura da lâmina de água sendo a produção de grãos reduzida $61,5 \%$ devido à competição das plantas daninhas com a cultura.
\end{abstract}

Termos de indexação: arroz, plantas daninhas, lâmina de água, momento de admissāo de água.

\section{ABSTRACT \\ WEED CONTROL IN LOWLAND RICE, USING WATER APPLICATION MOMENT AND WATER DEPHTS}

This research was carried out at the "Experimental Edgárdia Farm" - State of São Paulo University, Campus of Botucatu - Brazil, during the growing season of 1990/91. The objective was to evaluate the effect of water depths and the beginning of water application on the weed development and rice yield. Three water dephts $(5,10$ and $15 \mathrm{~cm})$; three water application moments $(15,42$ and 74 days after

( ${ }^{\text {) }}$ Parte da dissertaçăo de mestrado do primeiro autor, apresentada à Faculdade de Ciências Agronômicas, UNESP, Câmpus de Botucatu. Recebido para publicaçāo em 27 de setembro de 1994 e aceito em 22 de agosto de 1995.

$\left(^{2}\right)$ Seção de Algodão, Instituto Agronômico (IAC), Caixa Postal 28, 13001-970 Campinas (SP).

(3) Departamento de Agricultura e Melhoramento Vegetal, FCA/UNESP, Caixa Postal 233, $18603-970$ Botucatu (SP).

$\left({ }^{4}\right)$ Com bolsa de pesquisa do CNPq. 
crop emergence) and weed management (weeded and unweeded) were tested in a randomized complete block design, arranged in split-splitplots. The moments were the main plots; the water depths, the splitplots and the weed management, the split-splitplots. The weed development was affected by the water depths and water application moments. The grain yield was reduced in $61.5 \%$ by the weed competition with the rice crop.

Index terms: rice, weeds, water depths; water application moments.

\section{INTRODUÇÃO}

$\mathrm{O}$ arroz (Oryza sativa L.), base alimentar de dois terços da população mundial, ocupa uma área de 130 milhões de hectares, sendo $90 \%$ no sistema de cultivo irrigado. No Brasil, o sistema de cultivo predominante é o de sequeiro, que ocupa $76 \%$ da área cultivada e é responsável por $60 \%$ da produção. O irrigado, com $12 \%$ apenas da área cultivada, é responsável por $30 \%$ (Ferreira et al.,1983), com uma produtividade de $4 \mathrm{t} / \mathrm{ha}$, índice alto em relação ao do arroz-de-sequeiro $(1,5 \mathrm{t} / \mathrm{ha})$, mas significativamente inferior do da produtividade de alguns países asiáticos, como o Japão, que alcança a marca de $8 \mathrm{t} / \mathrm{ha}$. A produtividade inferior do arroz irrigado por inundação, no Brasil, deve-se à qualidade de várias técnicas culturais, dentre as quais se destacam o nivelamento da área, o preparo do solo, o controle de pragas e doenças e, principalmente, o controle das plantas daninhas e o manejo da água de irrigação inadequados.

Atualmente, um dos maiores problemas na cultura do arroz irrigado é a alta incidencia de plantas daninhas, sobretudo do arroz-vermelho (Oriza sativa L.), do capim-arroz (Echinochloa spp.) e da tiririca (Cyperus sp.), cuja ocorrência varia de região para região (Gelmini, 1982). Estudos sobre o manejo de água na cultura do arroz irrigado reportam que o momento correto de admissão de água e a altura da sua lâmina, podem influir, direta ou indiretamente, sobre a cultura, facilitando ou dificultando o desenvolvimento das plantas daninhas, que, ao competir por água, luz e nutrientes, acabam por afetar a produção de grãos. O objctivo deste trabalho foi avaliar os efeitos do momento de admissão e da altura da lâmina de água sobre a incidência das plantas daninhas e a produção de grãos.

\section{MATERIAL E MÉTODOS}

Desenvolveu-se o presente trabalho na Fazenda Experimental Edgárdia, definida pelas seguintes coordenadas geográficas: $435 \mathrm{~m}$ de altitude, $22^{\circ} 48^{\prime} \mathrm{S}$ de latitude e $48^{\circ} 23^{\prime} \mathrm{W} \mathrm{GrW}$, com clima do tipo Cfa, temperado, sem inverno, seco, segundo a classificação de Köppen (Setzer, 1946), e solo classificado como aluvial por Tosin et al. (1972).

$O$ delineamento experimental empregado foi de blocos ao acaso em parcelas subsubdivididas, com quatro repetições.

Os tratamentos constituíram-se de três momentos de admissão de água: aos 15, 42 e 74 dias após a emergência das plantas de arroz, M1, M2 e M3 respectivamente.

Os momentos de admissão de água constituíram as parcelas, com uma área útil de $48 \mathrm{~m}^{2}$.

Mediante a subdivisāo das parcelas com taipas de contenção, foi possível utilizar três alturas de lâmina de água $(5,10$ e $15 \mathrm{~cm})$, constituindo as subparcelas, que foram divididas por estacas que demarcaram os tratamentos com e sem capina (manejo das plantas daninhas). Efetuava-se a capina para manter as subsubparcelas livres da infestação de plantas daninhas durante todo o ciclo.

Realizou-se a semeadura manual em 28 de dezembro de 1990, em doze linhas espaçadas de $25 \mathrm{~cm}$ em cada parcela, utilizando-se uma densidade de cem sementes por metro linear da variedade IAC 242.

Efetuou-se adubação em cobertura em 25/3/91 durante o início de formacão da panícula, denominado "ponto-algodão", na base de $40 \mathrm{~kg} / \mathrm{ha}$ de $\mathrm{N}$ e $40 \mathrm{~kg} / \mathrm{ha}$ de $\mathrm{K}_{2} \mathrm{O}$. 
Obtiveram-se dados referentes ao levantamento das plantas daninhas da área, no momento de admissão de água e na colheita. Assim, coletaram-se os dados sobre número total de plantas daninhas por metro quadrado, massa seca das plantas daninhas por hectare, número de plantas de capim-arroz (Echinochloa sp.) e tiririca (Cyperus sp.) por metro quadrado e porcentagem de redução da massa seca das plantas daninhas (RMS), calculada pela seguinte fórmula:

onde:

$$
\% \text { RMS }=\frac{\text { MS na colheita }}{\text { MS na admissão de água }}
$$

\% RMS = porcentagem de redução da massa seca; MS = massa seca das plantas daninhas.

Para essas avaliações, consideraram-se duas amostras de $0,25 \mathrm{~m}^{2}$, correspondendo a $0,5 \mathrm{~m}^{2} \mathrm{da}$ área útil de cada parcela.

Obteve-se, ainda, a massa de grãos da área útil de cada parcela, transformadas através de cálculo em produtividade por hectare.

Analisaram-se os dados relativos ao desenvolvimento das plantas daninhas pela comparação simples de médias e os de produtividade de grãos, pela comparação de médias mediante o teste de Tukey a $5 \%$ de probabilidade.

\section{RESULTADOS E DISCUSSÃo}

A emergência das plantas de arroz iniciou-se em 7 de janeiro de 1991, atingindo $50 \%$ no dia 15, com desenvolvimento uniforme e vigoroso durante todo o ciclo. As plantas dos momentos M1, M2 e M3 atingiram, respectivamente, os seus pontos de colheita aos 137, 147 e 161 dias após a emergência.

O atraso na admissão de água determinou o prolongamento do ciclo da cultura, tal como Alves (1990) havia verificado.

Os dados referentes ao número de plantas daninhas por metro quadrado, por ocasião da admissão de água nos diferentes momentos, constam do qua- dro 1. Comparando-os, pode-se constatar que não ocorreram diferenças no número de plantas daninhas, entre as subparcelas.

Tais dados demonstram a uniformidade de distribuição das plantas daninhas na área experimental, possibilitando estudar o efeito do manejo de água sobre essa comunidade. Entretanto, à medida que se atrasou a admissão de água dos momentos M1 e M2 para M3, houve redução no número de plantas daninhas. As diferentes densidades de plantas daninhas nas parcelas talvez sejam devidas a uma competição inter- e intra-específica. Esse resultado era esperado em virtude da concorrência entre as plantas daninhas: as espécies mais vigorosas inibem o desenvolvimento das demais.

O número de plantas de tiririca (Cyperus sp.) por metro quadrado, antes da admissão de água, foi diretamente proporcional ao número total de plantas daninhas por metro quadrado (Quadro 2). Assim, quando houve uma redução de plantas daninhas por metro quadrado, verificou-se a mesma tendência para o número de plantas de tiririca por metro quadrado, as quais atingiram crescimento máximo no momento intermediário de admissão de água (M2), decrescendo no último momento.

Tal fato mostra que o desenvolvimento da população passa a ser influenciado também pelo seu ciclo, ou seja, muitas plantas atingiram a senescência antes do último momento de admissão de água.

A ocorrência de plantas de capim-arroz por ocasião da admissão de água (Quadro 3) foi visivelmente menor, diferenciando-se da tiririca. Com o atraso na admissão do primeiro momento (M1) para os seguintes (M2 e M3), houve pequena redução do número de plantas de capim-arroz. Apesar da redução do total de plantas daninhas em M3, o número de plantas de capim-arroz mostrou-se praticamente inalterado entre M2 e M3. A tiririca, ao contrário, teve seu número reduzido em M3.

Pelos dados referentes ao número de plantas de capim-arroz na colheita (Quadro 4), pode-se constatar, em todas as parcelas, sensível redução de população, causada ou pela ação da água, ou pela competição inter-e intra-específica, ou, ainda, pela 
senescência em vista do próprio ciclo. Não se observou tiririca na colheita, apenas capim-arroz, demonstrando, dessa forma, o diferente comportamento dessa espécie, quando comparada à tiririca. Contudo, deve-se ressaltar que, apesar de a população final ser constituîda apenas de capim-arroz, o número de plantas dessa espécie daninha também foi virtualmente reduzido pelo controle da água $\mathrm{e}$ pela concorrência interespecífica.

A contagem do capim-arroz por ocasião da colheita (Quadro 4) revela que a lâmina de água de $15 \mathrm{~cm}$ (L15) apresenta número sensivelmente menor em relação às de 5 e $10 \mathrm{~cm}$ (L5 e L10). Esses resultados confirmam os de Barros \& Porto (1979), que verificaram bom controle das plantas daninhas com lâmina de água maior que $10 \mathrm{~cm}$.
Ao atraso na admissão de água, seguiu-se um aumento do número de plantas de capim-arroz, na colheita (Quadro 4); esse número, porém, é pequeno quando comparado ao da população inicial da mesma espécie (Quadro 3), cujos valores se revelam 11 e 6 vezes maiores que o da população final em M2 e M3 respectivamente.

Quanto à lâmina de $15 \mathrm{~cm}$ (L15), administrada no primeiro momento, deve-se destacar o controle de todas as 121 plantas de capim-arroz detectadas por ocasião da admissão da água (Quadros $3 \mathrm{e}$ 4). Comparando-os, observa-se que o aumento da altura da lâmina de água em M1 reduziu o número de plantas de capim-arroz aos níveis de 91, 95 e 100\% para as lâminas de 5,10 e $15 \mathrm{~cm}$ respectivamente.

Quadro 1. Médias do número total de plantas daninhas por metro quadrado por ocasião da admissão de água

\begin{tabular}{|c|c|c|c|c|}
\hline \multirow{2}{*}{$\begin{array}{c}\text { Altura } \\
\text { das lâminas }\end{array}$} & \multicolumn{3}{|c|}{ Momentos ( $\left.{ }^{1}\right)$} & \multirow{2}{*}{ Média } \\
\hline & M1 & M2 & M3 & \\
\hline \multicolumn{5}{|l|}{$\mathrm{cm}$} \\
\hline L5 & 721,50 & 884,00 & 524,00 & 709,80 \\
\hline L10 & 852,00 & 969,50 & 596,00 & 805,80 \\
\hline L15 & 730,50 & 830,00 & 652,00 & 737,80 \\
\hline Média & 768,00 & 894,50 & 590,80 & -- \\
\hline
\end{tabular}

( $\left.{ }^{\mathrm{l}}\right)$ M1, M2 e M3 = admissão de âgua aos 15,42 e 74 dias respectivamente.

Quadro 2. Médias do número de plantas de tiririca por metro quadrado, por ocasião da admissão de água

\begin{tabular}{|c|c|c|c|c|}
\hline \multirow{2}{*}{$\begin{array}{c}\text { Altura } \\
\text { das lâminas }\end{array}$} & \multicolumn{3}{|c|}{ Momentos $\left({ }^{l}\right)$} & \multirow{2}{*}{ Média } \\
\hline & $\mathrm{MI}$ & M2 & M3 & \\
\hline \multicolumn{5}{|l|}{$\mathrm{cm}$} \\
\hline L5 & 595,50 & 653,50 & 365,50 & 537,80 \\
\hline L10 & 750,50 & 785,00 & 441,00 & 658,80 \\
\hline L15 & 595,50 & 629,50 & 522,00 & 582,30 \\
\hline Média & 647,16 & 689,33 & 442,50 & -- \\
\hline
\end{tabular}

(1) M1, M2 e M3 = admissão de água aos 15, 42 e 74 dias respectivamente. 
Em M2, as reduções do número de plantas daninhas por metro quadrado foram de 89,90 e $93 \%$ para as lâminas de 5,10 e $15 \mathrm{~cm}$ respectivamente. Efetuando-se a admissão de água no momento M3, os nívcis de controle foram de 81,81 e $93 \%$ para as lâminas 5,10 e $15 \mathrm{~cm}$ respectivamente.

Calegaro \& Bauer (1983) constataram perdas de 16 e 77\% na produção de grãos com, respectivamente, 5 e 80 plantas de capim-arroz por metro quadrado.

No presente trabalho, o melhor indicativo do dano potencial causado pelas plantas daninhas à cultura é o número das remanescentes na colheita (Quadro 4).

Mediante o atraso na admissão de água, as plantas daninhas puderam competir com a cultura por mais tempo. Assim sendo, quando se admitiu água em M2 e M3 e se utilizou a maior lâmina (L15), em parcelas sem capina, houve reduções de $8,6 \mathrm{e}$ $59 \%$, respectivamente, na produção de grãos, quando comparada à admissão no primeiro momento (M1) (Quadro 8). Da mesma forma, os estudos de Smith Jr. (1967) mostram que, à medida que se aumenta a população do capim-arroz de 9 para 46 plantas por metro quadrado, ocorre uma redução na produção de 57 e $95 \%$ respectivamente.

Os dados referentes à massa seca das plantas daninhas na admissão de água encontram-se no quadro 5: constata-se que não houve diferença em relação à quantidade, expressa em massa seca, de plantas daninhas existentes tanto nas parcelas (momentos de admissão de água) como nas subparcelas (altura das lâminas de água). Constata-se, também, que a área experimental apresentou distribuição uniforme das plantas daninhas.

Quadro 3. Médias do número de plantas de capim-arroz por metro quadrado por ocasião da admissão de água

\begin{tabular}{ccccr}
\hline \multirow{2}{*}{$\begin{array}{c}\text { Altura } \\
\text { das lâminas }\end{array}$} & \multicolumn{3}{c}{ Momentos $\left(^{1}\right)$} & Média \\
\cline { 2 - 4 } & M1 & M2 & M3 \\
\hline cm & & & 111,50 \\
L5 & 107,50 & 105,00 & 103,00 & 108,00 \\
L10 & 101,00 & 94,50 & 79,00 & 99,50 \\
L15 & 121,00 & 87,00 & 97,90 & 95,80 \\
Média & 109,83 & 95,50 & & - \\
\hline
\end{tabular}

(') M1, M2 e M3 = admissão de água aos 15, 42 e 74 dias respectivamente.

Quadro 4. Médias do número de plantas de capim-arroz por metro quadrado por ocasião da colheita obtidas para tratamentos

\begin{tabular}{|c|c|c|c|c|}
\hline \multirow{2}{*}{$\begin{array}{c}\text { Altura } \\
\text { das lâminas }\end{array}$} & \multicolumn{3}{|c|}{ Momentos $\left({ }^{1}\right)$} & \multirow{2}{*}{ Média } \\
\hline & M1 & M2 & M3 & \\
\hline \multicolumn{5}{|l|}{$\mathrm{cm}$} \\
\hline L5 & 9,50 & 11,50 & 21,50 & 14,18 \\
\hline L10 & 4,50 & 9,00 & 19,50 & 11,00 \\
\hline L 15 & 0,00 & 5,50 & 5,50 & 3,66 \\
\hline Média & 4,66 & 8,66 & 15,50 & -- \\
\hline
\end{tabular}


Tanto a admissão de água em momentos iniciais (M1 e M2) quanto a maior altura da lâmina afetaram a massa seca das plantas daninhas na colheita, diminuindo-a (Quadro 6).

O momento de admissão de água influiu na redução da massa seca das plantas daninhas, atingindo a ordem de $90,02 \%$ - Quadro 7. O atraso na admissão determinou uma diminuição da massa seca das plantas daninhas nas parcelas, podendo-se explicá-la pela competição intra- e interespecífica que aumenta no decorrer do ciclo, e pelo processo senescente das plantas. Dessa forma, quer se adie o momento de admissão de água, quer se aumente a altura da lâmina, ocorre diminuição da massa seca das plantas daninhas na colheita.

Analisando-se os dados para a porcentagem de redução da massa seca das plantas daninhas (Qua- dro 7), constata-se que a altura da lâmina de água influiu significativamente sobre tal parâmetro, provocando uma redução superior a $66 \%$ na massa seca. Por outro lado, lâminas maiores reduziram a massa seca, indicando que a altura da lâmina de água exerceu um controle diferenciado dessas plantas.

Assim, a lâmina de $15 \mathrm{~cm}$ (L15) reduziu o peso da matéria seca das plantas daninhas em 100,84,9 e $95,2 \%$ para os momentos M1, M2 e M3 respectivamente (Quadro 7). Por outro lado, não se detectou massa seca de plantas daninhas quando se utilizou uma lâmina de $15 \mathrm{~cm}$ (L15) no momento de admissão M1, obtendo-se um controle total das plantas daninhas. Tal fato demonstra que, mesmo com bom controle pelo uso de lâminas maiores, a admissão de água não deve ser retardada, a fim de evitar que se prolongue o período de competição das plantas daninhas com a cultura.

Quadro 5. Médias da massa seca das plantas daninhas por ocasião da admissão de água em diferentes momentos

\begin{tabular}{|c|c|c|c|c|}
\hline \multirow{2}{*}{$\begin{array}{c}\text { Altura } \\
\text { das lâminas }\end{array}$} & \multicolumn{3}{|c|}{ Momentos $\left({ }^{l}\right)$} & \multirow{2}{*}{ Média } \\
\hline & M1 & M2 & M3 & \\
\hline $\mathrm{cm}$ & & \multicolumn{2}{|c|}{$\mathrm{kg} / \mathrm{ha}$} & \\
\hline L5 & 285,50 & 287,80 & 235,00 & 269,40 \\
\hline $\mathrm{L} 10$ & 278,00 & 254,00 & 257,30 & 263,20 \\
\hline LI5 & 195,30 & 211,00 & 326.30 & 244,20 \\
\hline Médias & 252,90 & 250,90 & 272,90 & - \\
\hline
\end{tabular}

( $\left.{ }^{1}\right)$ M1, M2 e M3 = admissāo de água aos 15, 42 e 74 dias respectivamente.

Quadro 6. Médias da massa seca das plantas daninhas por ocasião da colheita, obtidas para tratamentos

\begin{tabular}{|c|c|c|c|c|}
\hline \multirow{2}{*}{$\begin{array}{c}\text { Altura } \\
\text { das lâminas }\end{array}$} & \multicolumn{3}{|c|}{ Momentos $\left({ }^{1}\right)$} & \multirow{2}{*}{ Média } \\
\hline & M1 & M2 & M3 & \\
\hline \multicolumn{5}{|c|}{$\mathrm{kg} / \mathrm{ha}$} \\
\hline L5 & 263,75 & 417,00 & 710,41 & 463,47 \\
\hline L10 & 153,50 & 418,25 & 628,00 & 399,90 \\
\hline L 15 & 0,00 & 192,50 & 164,05 & 118,85 \\
\hline Média & 139,08 & 343,58 & 500,82 & - \\
\hline
\end{tabular}


Neste trabalho, houve melhor controle das plantas daninhas quando a admissão de água se processou aos 15 e aos 42 dias após a emergência da cultura; processando-a aos 74 dias, a competição das plantas daninhas foi prejudicial ao desenvolvimento da cultura. Dessa forma, observou-se o crescimento das plantas daninhas, não havendo diferença na massa seca, por ocasião da admissão de água (Quadro 5).

De maneira geral, pode-se dizer que a lâmina de água controlou, com eficiência, as principais plantas daninhas presentes na área experimental, e que, à medida que se atrasa a admissão de água e se utiliza lâmina de menor altura, há redução do nível de controle (Quadro 7).
Segundo Souza \& Alcântara (1984), quanto mais tarde for iniciada a admissão de água, mais profunda deverá ser a lâmina para bom controle das plantas daninhas.

As tendências verificadas no presente trabalho estão de acordo com as recomendações de Guimarães et al. (1974) e Gondin (1983), que preconizam o início da irrigação até 20 dias após a emergência da cultura para obtenção de bom controle das plantas daninhas.

No que concerne ao controle de várias espécies de plantas daninhas sob condição de inundação, os resultados deste trabalho vão ao encontro dos

Quadro 7. Médias de porcentagem de redução da massa seca de plantas daninhas, obtidas para tratamentos

\begin{tabular}{|c|c|c|c|c|}
\hline \multirow{2}{*}{$\begin{array}{c}\text { Altura } \\
\text { das lâminas }\end{array}$} & \multicolumn{3}{|c|}{ Momentos $\left({ }^{1}\right)$} & \multirow{2}{*}{ Média } \\
\hline & Ml & M2 & M3 & \\
\hline \multicolumn{5}{|l|}{$\mathrm{cm}$} \\
\hline L5 & 83,32 & 82,75 & 66,02 & 77,36 \\
\hline L10 & 86,75 & 80,00 & 73,45 & 80,06 \\
\hline $\mathrm{L} 15$ & 100,00 & 84,90 & 95,20 & 93,36 \\
\hline Média & 90,02 & 82,55 & 78,22 & -- \\
\hline
\end{tabular}

(') M1, M2 e M3 = admissão de água aos 15,42 e 74 dias respectivamente.

Quadro 8. Médias da produtividade de grãos obtidas para tratamentos

\begin{tabular}{|c|c|c|c|c|c|c|}
\hline \multirow{2}{*}{$\begin{array}{c}\text { Altura } \\
\text { das lâminas }\end{array}$} & \multirow{2}{*}{$\begin{array}{l}\text { Manejo das plan- } \\
\text { tas daninhas }\end{array}$} & \multicolumn{3}{|c|}{ Momentos $\left({ }^{1}\right)$} & \multirow{2}{*}{$\begin{array}{l}\text { Médias } \\
\text { de CC e SC }\end{array}$} & \multirow{2}{*}{$\begin{array}{l}\text { Médias } \\
\text { de lâmina }\end{array}$} \\
\hline & & $\mathrm{Ml}$ & $\mathrm{M} 2$ & M3 & & \\
\hline $\mathrm{cm}$ & & & 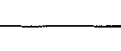 & $\mathrm{kg} / \mathrm{ha}$ & . & \\
\hline \multirow[t]{2}{*}{ L5 } & $\mathrm{CC}$ & 3383 & 3540 & 2575 & 3166 & \\
\hline & $\mathrm{SC}$ & 1343 & 1424 & 563 & 1110 & $2138 \mathrm{a}$ \\
\hline \multirow[t]{2}{*}{$\mathrm{L} 10$} & $\mathrm{CC}$ & 3248 & 2593 & 3137 & 2993 & \\
\hline & $\mathrm{SC}$ & 1285 & 1583 & 906 & 1258 & $2125 \mathrm{a}$ \\
\hline \multirow[t]{2}{*}{ L 15} & $\mathrm{CC}$ & 3168 & 3635 & 2349 & 3051 & \\
\hline & $\mathrm{SC}$ & 1518 & 1387 & 624 & 1176 & $2114 a$ \\
\hline \multirow[t]{2}{*}{ Média } & & $2324 \mathrm{~A}$ & $2360 \mathrm{~A}$ & $1692 B$ & Com capina & $3070 a$ \\
\hline & & & & & Sem capina & $1182 b$ \\
\hline
\end{tabular}

(') M1, M2 e M3 = admissão de água aos 15, 42 e 74 dias respectivamente. Médias seguidas por mesma letra, maiúscula na horizontal e minúscula na vertical, não diferem entre si pelo teste de Tukey a $5 \%$ de probabilidade. O coeficiente de variação para a análise foi de $33,76 \%$. 
Quadro 9. Médias de porcentagem de redução da produtividade de grãos, obtidas para tratamentos

\begin{tabular}{|c|c|c|c|c|}
\hline \multirow{2}{*}{$\begin{array}{c}\text { Altura } \\
\text { das lâminas }\end{array}$} & \multicolumn{3}{|c|}{ Momentos $\left({ }^{1}\right)$} & \multirow{2}{*}{ Média } \\
\hline & M1 & M2 & M3 & \\
\hline \multicolumn{5}{|l|}{$\mathrm{cm}$} \\
\hline L5 & 60,30 & 59,70 & 78,13 & 64,93 \\
\hline L 10 & 60.43 & 38,95 & 71,11 & 57,96 \\
\hline L15 & 52,80 & 53,49 & 74,22 & 61,50 \\
\hline Média & 57,60 & 53,49 & 74,22 & 61,50 \\
\hline
\end{tabular}

(') M1, M2 e M3 = admissão de águra aos 15,42 e 74 dias respectivamente.

de Smith \& Fox (1973), Silva \& Araújo (1977) e DNOCS (1972). Quanto à redução da infestação de plantas daninhas pelo aumento de altura de lâminas, há correlação destes resultados com os de Vega \& Paller Jr. (1975) e Barros \& Porto (1979).

Analisando-se os quadros 8 e 9, verifica-se uma redução na produção de grãos, da ordem de $61,5 \%$, ocasionada pela competição das plantas daninhas com a cultura do arroz. Verifica-se, ainda, que as alturas de lâmina de água não afetaram a produtividade de grãos e que a admissão de água, efetuada em M3, propiciou valores de produtividade de grãos significativamente inferiores àqueles obtidos em M1 c M2.

Pelo quadro 9, observa-se que o índice de menor redução na produção de grãos, em função da presença das plantas daninhas, foi obtido através da utilização da lâmina de água de $10 \mathrm{~cm}$ e da admissão aos 42 dias. A admissão aos 74 dias reduziu $74,22 \%$ a produção de grãos. Não se observaram interações significativas entre momento x lâmina, momento $x$ capina, capina $x$ lâmina e capina $x$ lâmina $x$ momento.

\section{CONCLUSÃO}

A competição das plantas daninhas, principalmente a tiririca e o capim-arroz, diminuiu $61,5 \%$ a produção de grãos. O capim-arroz persistiu até a colheita com o uso da lâmina de $5 \mathrm{~cm}$; no entanto, teve sua população reduzida com o aumento da lâmina de água para 10 e $15 \mathrm{~cm}$. A tiririca foi controlada com eficiência por todas as alturas de lâmina em todos os momentos de admissão de água. O maior período de convivência das plantas daninhas com a cultura antes da admissão reduziu a produção de grãos. A utilização da lâmina de maior espessura, combinada com a admissão de água no início de desenvolvimento das plantas de arroz, propiciou os melhores níveis de controle das plantas daninhas.

\section{REFERÊNCIAS BIBLIOGRÁFICAS}

ALVES, M.C. Efeitos do manejo de água na cultura de arroz (Oriza sativa L.) irrigado por inundação. Botucatu, 1990. 71p. Dissertação (Mestrado em Agronomia) - Faculdade de Ciências Agronômicas UNESP, 1990.

BARROS, L.C.G. \& PORTO, E.R. Efeitos da profundidade da lâmina de água sobre a incidência de plantas daninhas na cultura do arroz. Planta Daninha, Campinas, 11(2):69-72, 1979.

CALEGARO, P.R. \& BAUER, D. Plantas daninhas em arroz irrigado. Correio Agrícola Bayer, São Paulo, 2:536-539, 1983.

DEPARTAMENTO NACIONAL DE OBRAS CONTRA AS SECAS (DNOCS). Arroz irrigado. In: Contribuição ao estudo das culturas irrigadas. Recife, 1972. p.25-30. 
FERREIRA, M.E; YAMADA, T. \& MALAVOLTA, F. Cultura do arroz de sequeiro: fatores que afetam a produtividade. Piracicaba Instituto da Potassa \& Fosfato, 1983. p.15-34

GELMINI, G.A. Herbicidas para o controle de plantas daninhas em culturas de arroz irrrigado. Campinas, Coordenadoria de Assistência Técnica Integral, 1982. 11 p. (Boletim técnico, 159)

GONDIN, L.A.P. Irrigação e drenagem. Lavoura ar rozeira, Porto Alegre, 1983. v. 37, n.347.

GUIMARÃES, G; BARRETO, C.B. \& IGUE, T. Manejo da água para arroz semeado em várzea. I. Efeitos de drenagens intermediárias e finais. Campinas, Instituto Agronômico, 1974. 32p. (Boletim técnico, 17)

SETZER, J. Contribuição para o estudo do clima do Estado de São Paulo. São Paulo, Escolas Profissionais Salesianas, 1946. 239p.

SILVA, J.F. \& ARAÚJO, J.T. Estudos de diferentes lâminas d'água na cultura do arroz (Oriza sativa L.) no perïmetro irrigado de São Gonçalo. Boletim Técnico do Departamento Nacional de Obras Contra as Secas, Paraíba, 35(1):27-35, 1977.
SMITH JR., R.J. Weed competition in rice. Weed Science, Champaign, 16:252-255, 1967.

SMITH JR., R.J. \& FOX, W.T. Soil water and growth of rice and weeds. Weed Science, Champaign, 21(1):61-63, 1973 .

SOUZA, J.F. \& ALCÂNTARA, E.N. Plantas daninhas em arroz e seu controle. Informe Agropecuário, Belo Horizonte. 10(114):21-23, 1984

TOSIN, W.A.C.; ESPÍNDOLA, C.R. \& PACCOLA, A.A. Levantamento de solos da Fazenda Experimental de Botucatu. In: JORNADA CIENTÍFICA DA FACULDADE DE CIÊNCIAS MÉDICAS E BIOLÓGICAS DE BOTUCATU, 2, Botucatu, 1972. Anais. Botucatu, Associação dos Docentes, 1972. p.119.

VEGA, M.R.\& PALLER JR., E.C. Malas hierbas y como combatirlas. In: Universidade de Filipinas, Escuela de Agricultura. Caltivo de Arroz: manual de producción, México, Limusa, 1975. p.177-199. 